\title{
Research on Low-Carbon Economic Operation Strategy of Renewable Energy-Pumped Storage Combined System
}

\author{
Yuhong Chang, ${ }^{1}$ Shizhong Liu, ${ }^{2}$ Lei Wang, ${ }^{1}$ Wenbo Cong, ${ }^{2}$ Zilong Zhang $\mathbb{D},{ }^{2}$ \\ and Shaolong $\mathbf{Q i}^{2}$ \\ ${ }^{1}$ Operation Supervision Center, State Grid Xinyuan Company Ltd., Beijing 100761, China \\ ${ }^{2}$ Operation and Maintenance Department, Liaoning Pushihe Pumped Storage Co. Ltd., Beijing 100761, China \\ Correspondence should be addressed to Zilong Zhang; zhangzilong187@163.com
}

Received 30 December 2021; Revised 19 January 2022; Accepted 26 January 2022; Published 17 February 2022

Academic Editor: Rui Wang

Copyright (c) 2022 Yuhong Chang et al. This is an open access article distributed under the Creative Commons Attribution License, which permits unrestricted use, distribution, and reproduction in any medium, provided the original work is properly cited.

\begin{abstract}
Aiming at the problem of insufficient peak shaving capacity of the power system after large-scale renewable energy such as wind power and photovoltaics is connected to the grid, a new energy-pumped storage combined system low-carbon economic operation strategy is proposed. First, the energy storage characteristics of pumped storage are studied; wind power and photovoltaic output are shifted in time and space; and a new energy-pumped storage combined system model with photovoltaics, wind power, and pumped storage as the main body is established. Second, the carbon trading mechanism was introduced, and the reward and punishment ladder carbon trading cost model was established. Then, via the new energy-pumped storage combined system, the upper optimization target with the smallest investment cost and the lower optimization target with the largest system benefit are established, and a two-layer optimization model solution method based on linearly decreasing inertia weight particle swarm optimization and sequential quadratic programming algorithm is proposed. Finally, via the operating data of a pumped storage power station on an island in northern China, the new energy-pumped storage combined system low-carbon economic operation strategy was simulated and verified. The simulation results show that the low-carbon economic operation strategy of the new energy-pumped storage combined system proposed in this paper can effectively suppress load fluctuations, reduce the impact of wind and wind anti-peak regulation characteristics on the power grid, increase the utilization rate of renewable energy, and improve system economy.
\end{abstract}

\section{Introduction}

In recent years, with the national low-carbon strategy and policy support, a high proportion of wind power, photovoltaics, and other renewable energies has been connected to the power system. The volatility of wind power output and the characteristics of anti-peak regulation have brought great challenges to the peak regulation of the power system [1-3]. However, the frequent deep peak shaving of thermal power units greatly increases the cost of system peak shaving, increases unit losses, and reduces the economy of the system. Pumped storage power plants can provide a good solution for system auxiliary peak shaving due to their fast start-up, flexible methods, and low-carbon emissions [4-7]. However, the coordination and optimization effect of pumped storage and renewable energy output has not yet been fully utilized. At the same time, wind power, photovoltaics, and pumped storage are clean power generation methods that have low-carbon emissions during production and operation, but the system's component production, operation and maintenance, and recycling processes have relatively large carbon emissions, which are related to renewable energy-pumping. The optimal configuration of the energy storage combined system has a greater impact and cannot be ignored. Therefore, by combining the constraints of the carbon trading mechanism on carbon emissions, establishing a joint operation mode of wind power, photovoltaics, and pumped storage has the advantages of reducing system peak shaving costs, reducing deep peak shaving of thermal power units, stabilizing load fluctuations, and promoting the consumption of renewable energy. 
The pumped storage power station participates in the joint operation of wind and wind electric fields to smooth wind and wind power as a flexible resource. Literature [8] separately studied the output optimization of wind and solar storage systems in the heating period and nonheating period and verified the advantages of pumped storage power stations in improving the consumption of renewable energy. The literature [9] optimizes the wind storage operation mode based on the average value of the predicted power of wind power and proposes the wind storage bundling operation mode to increase the wind power absorption capacity. Literature [10] established the minimum optimization goal of abandoned air volume and proposed a coordinated operation mode of wind storage. The above studies have studied the operation mode of pumped storage power station to participate in the consumption of new energy power generation, but the energy coupling method is relatively simple, and the carbon trading mechanism has not been introduced.

At present, there has been a lot of research on the economic operation and capacity optimization of the windphotovoltaic-pumped storage combined system. Literature [11] proposed a capacity allocation method for photovoltaics, small-scale hydropower, and pumped storage hybrid energy systems based on market mechanisms, which improved the economics of hybrid energy systems. Literature [12] comprehensively considers the initial cost, replacement cost, and operation and maintenance cost; establishes the optimization goal of the minimum annual equivalent cost of the system; and optimizes the capacity of the wind and solar storage microgrid system. Literature [13] established an optimization goal for the minimum system load fluctuations and analyzed the economics of the new energy-pumped storage combined system. The above literature focuses on the optimal configuration problem of the joint operation system, but the optimal operation problem has not been considered, and the system economy cannot be fully improved.

Most of the above-mentioned research focuses on the capacity allocation of multisource systems such as wind and solar storage, aiming to eliminate the uncertainty of renewable energy, increase wind and solar grids, and improve the economic benefits of the joint system. However, no carbon trading mechanism has been introduced, and the multisource energy storage system lacks a unified and coordinated low-carbon economic operation strategy. This article coordinated and optimized the wind-photovoltaicpumped storage joint system to make the originally fluctuating wind and photovoltaic power generation a stable and dispatchable multisource energy storage system, achieving peak shifting and staggering valleys. The new energypumped storage combined system topology including wind power, photovoltaics, pumped storage power plants, and regional loads is constructed. Via wind-light-pumped storage combined system, carbon trading mechanism is introduced, and low-carbon economic operation models and strategies are proposed. Finally, via the operating data of a pumped storage power station on an island in northern China, simulation verification of the low-carbon economic operation strategy of the new energy-pumped storage combined system was conducted to verify the effectiveness of the proposed model and method.

\section{Renewable Energy-Pumped Storage Combined System Model}

The new energy-pumped storage combined system proposed in this article is a coordinated coupling system of power and water power for the peak shaving needs of the power system after large-scale renewable energy such as wind power and photovoltaics is connected to the grid. The joint operation relationship of wind and solar storage established in this article is shown in Figure 1. The new energy-pumped storage combined system consists of wind power, photovoltaics, and other renewable energy production equipment, and reversible pump-turbine generators are used as energy conversion equipment. The energy power station is used as energy storage equipment, the upper and lower reservoirs are used as energy storage media, and the energy interaction system was established by the control center. Through the coordination and optimization of the new energy-pumped storage combined system, the originally fluctuating wind and photovoltaic power generation becomes a stable and dispatchable multisource energy storage system, realizing peak shifting and staggering valleys.

\section{Wind Power Generation and Its Probability Distribution Model}

The output power of wind power mainly depends on the output power curve of the wind turbine, the height of the wind turbine hub, and its wind speed [14], which can be expressed as

$$
P_{w p}= \begin{cases}0, & S<S_{c i}, \\ \frac{P_{R}}{S_{R}^{3}-S_{c i}^{3}} S^{3}-\frac{P_{R}}{S_{R}^{3}-S_{c i}^{3}} S_{c i}^{3}, & S_{c i} \leq S<S_{R}, \\ P_{R}, & S_{R} \leq S<S_{c o} \\ 0, & S \geq S_{c o} .\end{cases}
$$

In the formula, $P_{w p}$ is the output power of the wind turbine; $P_{R}$ is the rated power of the wind turbine; $S$ is the actual wind speed at the height of the wind turbine hub; $S_{R}$ is the rated wind speed of the wind turbine; and $S_{c i}$ and $S_{c o}$ are the wind turbine power cut-in wind speed and cut-out wind speed.

The uncertainty of wind power can be represented by a wind speed probability distribution model. In the field of management science and engineering, some scholars have seen that the demand for a product is a Weibull distribution. Because the normal distribution is idealized, the Weibull distribution is closer to the actual situation of the long-tailed distribution of the probability density function of wind power. The two-parameter Weibull distribution model is 


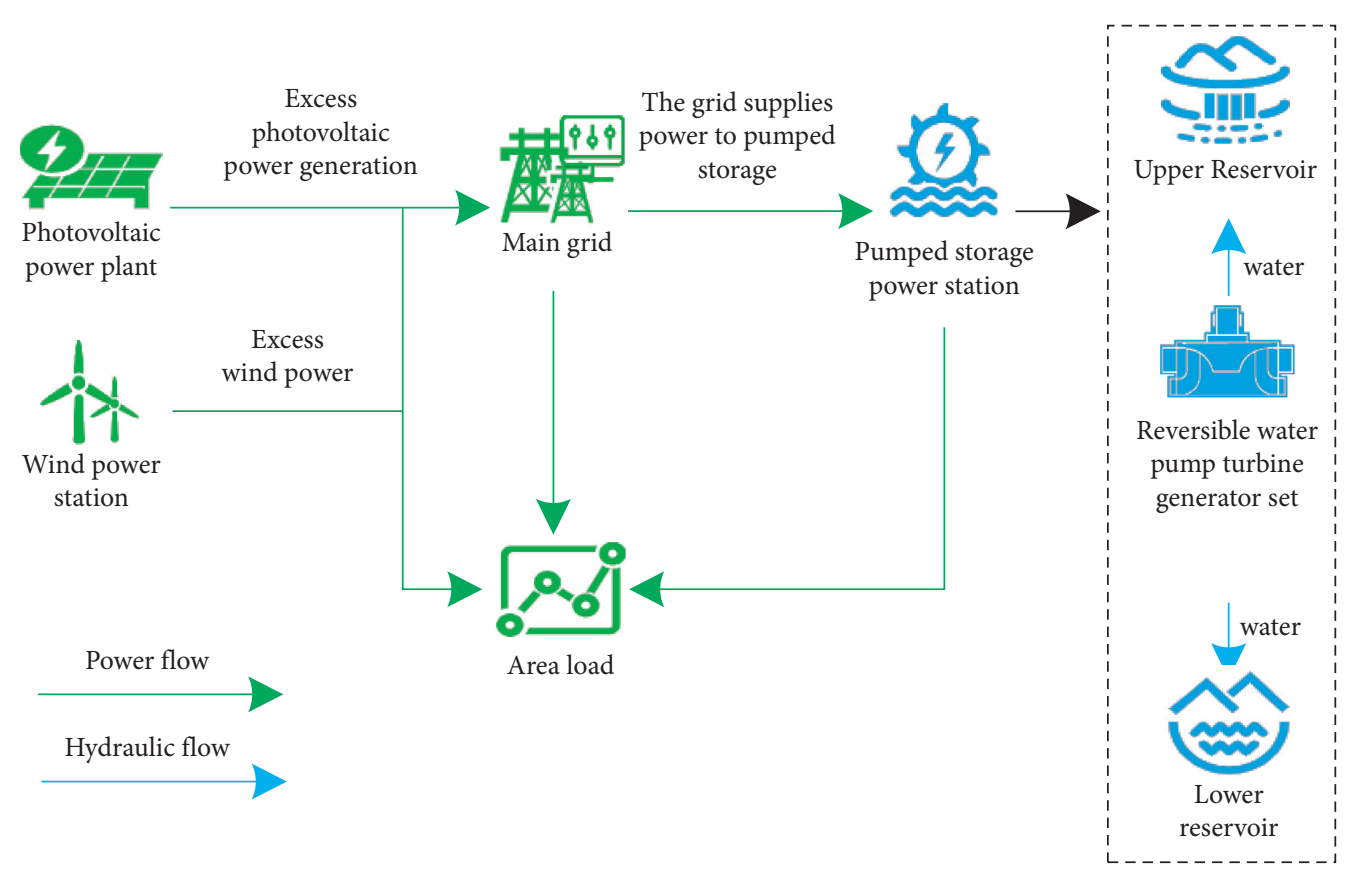

FIgURE 1: Topology structure of renewable energy-pumped storage combined system.

used by this paper to describe the probability density distribution of wind speed [15], which is expressed as

$$
\begin{aligned}
f_{1}(S) & =\frac{k}{c}\left(\frac{S}{c}\right)^{k-1} \exp \left(-\left(\frac{S}{c}\right)^{k}\right), \\
k & =\left(\frac{\sigma_{1}}{\mu_{1}}\right)^{-1.086}, \\
c & =\frac{\mu_{1}}{\Gamma(1+1 / k)} .
\end{aligned}
$$

In the formula, $\sigma_{1}$ and $\mu_{1}$ are the actual wind speed variance and mean value, respectively; $k$ and $c$ are the shape parameter and scale parameter of Weibull distribution respectively; and $\Gamma$ is the Gamma function.

\section{Photovoltaic Power Generation and Its Probability Distribution Model}

The output power of photovoltaic power generation mainly depends on the solar radiation intensity and temperature [16], which can be expressed as

$$
P_{P V}=P_{s} \eta_{\text {inv }} \eta_{\text {loss }} \eta_{\text {ref }} \frac{G}{1000}\left[1+\theta_{T}\left(T-T_{\text {ref }}\right)\right] \text {. }
$$

In the formula, $P_{s}$ is the rated power of photovoltaic power generation; $\eta_{i n v}$ is the inverter efficiency; $\eta_{\text {loss }}$ is the loss efficiency of photovoltaic power generation; $\eta_{\text {ref }}$ is the efficiency of photovoltaic power generation at a reference temperature; $G$ is the hourly average value of the solar radiation intensity on the surface of the photovoltaic power generation area; $\theta_{T}$ is the power temperature coefficient of photovoltaic power generation; and $T$ and $T_{\text {ref }}$ are the operating temperature and reference temperature of photovoltaic modules, respectively.
The uncertainty of photovoltaic power generation can be represented by a solar probability distribution model. Considering the actual situation that the Beta distribution is closer to the probability density function of photovoltaic power generation, the Beta distribution model is used in this paper to describe the probability density distribution of solar radiation intensity [17], which is expressed as

$$
\begin{aligned}
f_{2}(G) & =\frac{\Gamma(\alpha+\beta)}{\Gamma(\alpha) \Gamma(\beta)}\left(\frac{G}{G_{\max }}\right)^{a-1}\left(1-\frac{G}{G_{\max }}\right)^{\beta-1}, \\
\alpha & =\mu_{2}\left[\frac{\mu_{2}\left(1-\mu_{2}\right)}{\sigma_{2}^{2}}-1\right], \\
\beta & =\left(1-\mu_{2}\right)\left[\frac{\mu_{2}\left(1-\mu_{2}\right)}{\sigma_{2}^{2}}-1\right] .
\end{aligned}
$$

In the formula, $G_{\max }$ is the maximum solar radiation intensity during the simulation period; $\sigma_{2}$ and $\mu_{2}$ are the variance and mean value of the samples collected from the solar radiation intensity, respectively; and $\alpha$ and $\beta$ are the Beta distribution shape parameters.

\section{Pumped Storage Power Station Model}

The pumped storage power station is mainly composed of upper reservoir, lower reservoir, and reversible pump turbine. The pumping behavior of pumped storage power station is controlled according to the degree of load demand. When the load demand is low, the surplus electricity is used for pumping water by the pumped storage power station and stored in the upper reservoir. When the load demand is high, the pumped storage power station will deliver electrical energy to the system to meet the load demand. The smooth transition of thermal power units is realized, which is 
conducive to the regulation of the power system. The water volume of pumped storage can be expressed as

$$
\begin{aligned}
W(t+1) & =W(t)+\left(Q_{\text {rain }}(t)+Q_{p}(t)-Q_{h}(t)\right) \Delta t \\
Q_{p}(t) & =\frac{3600 \times 1000 \eta_{p} \eta_{w p} P_{p}(t)}{\rho g h} \\
& =K_{p} P_{p}(t) \\
Q_{h}(t)(t) & =\frac{3600 \times 1000 P_{h}(t)}{\eta_{h} \eta_{w p} \rho g h} \\
& =K_{h} P_{h}(t) .
\end{aligned}
$$

In the formula, $W(t)$ is the remaining water volume of the upper reservoir at time $t ; Q_{\text {rain }}(t)$ is the increased flow of rainfall in the upper reservoir; $\Delta t$ is the time interval; $Q_{p}(t)$ and $Q_{h}(t)$ are the flow of pumped storage in the pumping state and the power generation state, respectively; $\eta_{p}$ and $\eta_{h}$ are, respectively, reversible water pump-turbine unit storage efficiency and power generation efficiency; $\eta_{w p}$ is the pipeline efficiency; $P_{p}(t)$ and $P_{h}(t)$ are the storage power and generation power of the reversible water pumpturbine unit, respectively; $\rho$ is the density of water; $g$ is the acceleration of gravity; $h$ is the height of the head; and $K_{p}$ and $K_{h}$ are the flow-to-power ratios of pumped storage in the pumping state and the power generation state, respectively.

\section{Renewable Energy-Pumped Storage Combined System Operation Mode}

Renewable energy-pumped storage joint operation is the basis for formulating a low-carbon economic operation strategy for the new energy-pumped storage joint system. The operation mode of the new energy-pumped storage combined system is shown in Figure 2. The coupling between new energy power generation equipment and pumped storage power station is mainly reflected in the cooperation between pumping mode and power generation mode. The pumped storage power station adjusts its own operation mode according to the output of wind power and photovoltaics. Among them, $P_{L}(t), P_{e}(t)$, and $P_{p 2}(t)$ are the load demand at time $t$, the excess power of wind and solar power generation, and the pumping power provided by the main network, respectively. If $P_{\text {all }}(t)<P_{L}(t)$, the water volume of the upper reservoir decreases and the pumped storage power station is in power generation mode. If $P_{\text {all }}(t)>P_{L}(t)$, the upper reservoir starts to store water and the pumped storage is in pumping mode. During this period, if $P_{e}(t)>P_{p}(t)$, the pumped storage power station's pumping mode electricity is completely supplied by wind and solar power generation, and the surplus electricity is used for the large power grid and participates in carbon allowance trading. If $P_{e}(t)>P_{p}(t)$, the pumping mode of the pumped storage power station will give priority to wind and wind power generation, and the remaining demand will be purchased from the grid.

\section{Ladder Carbon Trading Model}

If the amount of carbon emissions generated is higher than their carbon allocation during the production and operation, the production enterprise needs to participate in the carbon trading market to purchase carbon emission rights. If the generated carbon emissions are lower than their carbon allocation, the enterprise can participate in the carbon trading market to sell this part of the carbon emission credits and then obtain benefits. The low-carbon economic characteristics of pumped storage power plants can be fully exploited by carbon trading, and the low-carbon emission reduction potential of production enterprises can be fully tapped [18].

7.1. Carbon Emission Allowance Allocation Model. The distribution of carbon emission rights includes purchased electricity and pumped storage power plants. The allocation of carbon emission rights can be expressed as

$$
\begin{gathered}
E=E_{e}+E_{p s}, \\
E_{e}=\delta_{e} \sum_{t=1}^{T} P_{e, t} \Delta t, \\
E_{p s}=\delta_{e} \sum_{t=1}^{T} P_{p s, t} \Delta t .
\end{gathered}
$$

In the formula, $E$ is the sum of the allocation quota of carbon emission rights; $E_{e}$ and $E_{p s}$ are the allocation quotas of carbon emission rights for purchased electric power and pumped storage power plants, respectively; $T$ is 24 periods of a day; $\Delta t$ is the time interval, which is $1 \mathrm{~h} ; \delta_{e}$ is the allocation of carbon emission rights per unit of power supply, taking $0.8 \mathrm{t} /(\mathrm{MWh}) ; P_{e, t}$ is the power purchased by the system from the grid during the $t$ period; and $P_{p s, t}$ is the power supplied by pumped storage.

7.2. System Operation Carbon Emission Model. Assuming that all electricity purchased from the large grid is produced by coal-fired power units, we can express the carbon emissions of each generating unit in the system as

$$
\begin{gathered}
E_{e, a}=\sum_{t=1}^{T}\left(a_{1}+b_{1} P_{e, t}+c_{1} P_{e, t}^{2}\right), \\
E_{p s, a}=\sum_{t=1}^{T}\left(a_{2}+b_{2} P_{p s, t}+c_{2} P_{p s, t}^{2}\right) .
\end{gathered}
$$

In the formula, $E_{e, a}$ and $E_{p s, a}$ are the carbon emission of purchased electricity and the carbon emission of pumped storage, respectively; $a_{1}, b_{1}$, and $c_{1}$ are the carbon emission coefficients of purchased coal for power generation; $a_{2}, b_{2}$, and $c_{2}$ are the carbon emission coefficients of pumped storage; $P_{e, t}$ is coal power supply power per unit time; and $P_{p s, t}$ is pumped storage power supply per unit time.

7.3. Carbon Trading Cost Model. Compensation coefficients are introduced into the calculation of carbon transaction 


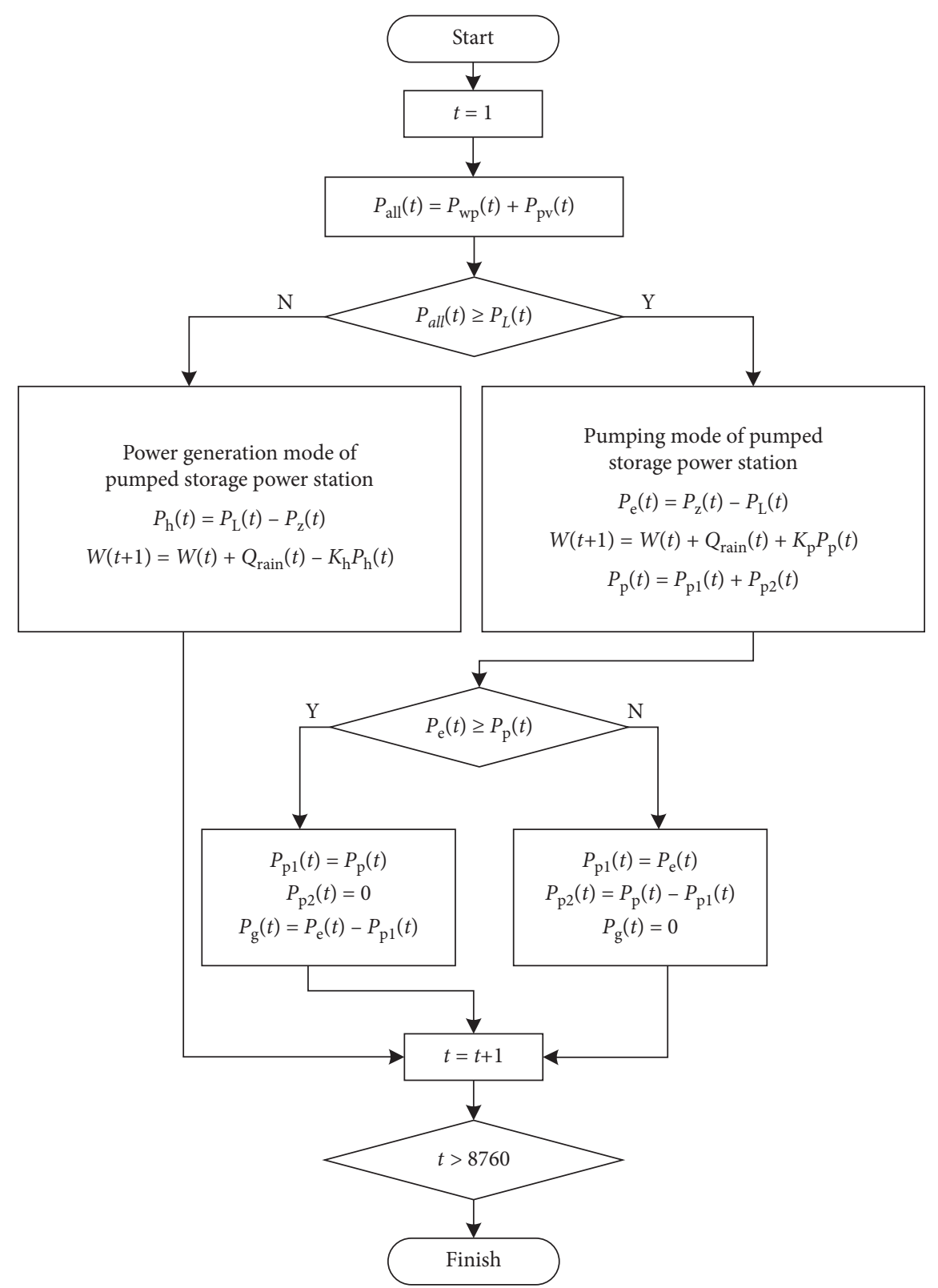

FIGURE 2: Renewable energy-pumped storage combined system operation mode.

costs to reward companies that actively participate in reducing emissions. When the system's carbon emissions are lower than the allocation of carbon emissions, carbon trading costs are negative. The carbon transaction cost calculation model is expressed as

$$
C_{c o_{2}}= \begin{cases}-\varepsilon(2+3 \beta) l+\varepsilon(1+3 \beta)\left(E_{a}-E_{s}+2 l\right), & E_{a} \leq E_{s}-2 l, \\ -\varepsilon(1+\beta) l+\varepsilon(1+2 \beta)\left(E_{a}-E_{s}+l\right), & E_{s}-2 l<E_{a} \leq E_{s}-l, \\ \varepsilon(1+\beta)\left(E_{a}-E_{s}\right), & E_{s}-l<E_{a} \leq E_{s}+l, \\ \varepsilon\left(E_{a}-E_{s}\right), & E_{s}<E_{a} \leq E_{s}+l, \\ \varepsilon l+\varepsilon(1+\alpha)\left(E_{a}-E_{s}-l\right), & E_{s}+l<E_{a} \leq E_{s}+2 l, \\ \varepsilon(2+\alpha) l+\varepsilon(1+2 \alpha)\left(E_{a}-E_{s}-2 l\right), & E_{s}+2 l<E_{a} \leq E_{s}+3 l, \\ \varepsilon(3+3 \alpha) l+\varepsilon(1+3 \alpha)\left(E_{a}-E_{s}-3 l\right), & E_{a}>E_{s}+3 l .\end{cases}
$$


In the formula, $\mathrm{C}_{\mathrm{co}_{2}}$ is the carbon transaction cost; $\varepsilon$ is the transaction price of the unit carbon emission rights quota; $\alpha$ is the increase in the price of carbon emission rights; $\beta$ is the compensation coefficient; and $l$ is the carbon emission range.

\subsection{Low-Carbon Economic Double-Layer Optimization} Model of Renewable Energy-Pumped Storage Combined System. The low-carbon economic double-layer optimization model of the renewable energy-pumped storage combined system has a master-slave hierarchical relationship structure [19-22]. It consists of two noncooperative relationship entities with objective functions and constraints. The upper-level investment decision objective function transfers the configuration plan to the lower level, and the lower-level optimization operation objective function performs optimization operation simulation on the upper-level investment decision objective function configuration plan and then transmits the optimization result to the upper level to guide the upper-level investment decision objective. Its mathematical expression is

$$
\begin{cases}\min _{x} F(x, y), & \text { s.t. }\left\{f_{1}(x, y) \leq 0, \ldots, f_{n}(x, y) \leq 0\right\}, \\ \min _{y} G(x, y), & \text { s.t. }\left\{g_{1}(x, y) \leq 0, \ldots, g_{n}(x, y) \leq 0\right\} .\end{cases}
$$

In the formula, $F(x, y)$ and $G(x, y)$ are the upper and lower objective functions, respectively; $f_{n}(x, y)$ and $g_{n}(x, y)$ are the upper and lower constraints; and $x$ and $y$ are the upper and lower decision variables, respectively.

\section{Upper-Level Optimization Model}

8.1. Objective Function. The upper-level optimization goal is to minimize the total investment cost recovery period, that is, the ratio of the total cost to the operating revenue. It can be expressed as

$$
\begin{aligned}
\min (\mathrm{RY})= & \min \left\{\frac{C_{w p}+C_{p v}+C_{\text {pump }}}{\max C_{e}}\right\}, \\
C_{w p}= & C_{w} N_{w}+\frac{C_{r e_{-} w} N_{w}}{(1+r)^{T_{w}}}+\sum_{n=1}^{T_{a}} \frac{C_{\text {om_w }} N_{w}}{(1+r)^{n}}, \\
C_{p v}= & C_{p} N_{p}+\frac{C_{r e_{-} p} N_{p}}{(1+r)^{T_{p}}}+\sum_{n=1}^{T_{a}} \frac{N_{p}}{(1+r)^{n}}, \\
C_{\text {pump }}= & C_{\text {pump_cap }} V_{\text {pump_cap }}+C_{\text {pump_power }} P_{\text {pump_power }}+ \\
& \sum_{n=1}^{T_{a}} \frac{C_{\text {OM_pc }} V_{\text {pump_cap }}+C_{\text {OM_pp }} V_{\text {pump_power }}}{p_{p}(1+r)^{n}}+\frac{C_{\text {re_pp }} V_{\text {pump_power }}}{(1+r)^{T_{\text {pump }}}} .
\end{aligned}
$$

In the formula, RY is the cost recovery period of the new energy-pumped storage system under the maximum economic benefit; $C_{w p}$ is the total cost of wind power generation; $C_{p v}$ is the total cost of photovoltaic power generation; $C_{\text {pump }}$ is the total cost of the pumped storage power station; $C_{e}$ is the sale electricity revenue; $C_{w}$ is the unit price of the wind turbine; $N_{w}$ is the number of wind turbines; $C_{r e_{-} w}$ is the replacement cost of the wind turbine; $C_{o m_{-} w}$ is the operation and maintenance cost of the wind turbine; $r$ is the discount rate; $T_{w}$ is the cost of the wind turbine life cycle; $T_{a}$ is the project cycle; $C_{p}$ is the unit price of photovoltaic cells; $N_{p}$ is the number of photovoltaic cells; $C_{r e_{-} p}$ is the replacement cost of photovoltaic cells; $C_{o m_{-} p}$ is the operation and maintenance cost of photovoltaic cells; $T_{p}$ is the life cycle of photovoltaic cells; $C_{\text {pump_cap }}$ is pumped storage unit price of the unit capacity of the upper reservoir of the power station; $V_{\text {pump_cap }}$ is the storage capacity of the upper reservoir of the pumped storage power station; $P_{\text {pump_power }}$ is the installed capacity of the reversible pump turbine of the pumped storage power station; $C_{\text {pump_power }}$ is the unit price per kilowatt of the installed turbine capacity of the pumped storage power station; $\mathrm{C}_{\mathrm{OM}_{-} p c}$ is the operation and maintenance cost per unit capacity of the upstream storage capacity of the pumped storage power station; $C_{O M_{-} p p}$ is the operation and maintenance cost per kilowatt of the pumped storage power station; $C_{r e_{-} p p}$ is the replacement cost of the reversible pump turbine of the pumped storage power station; and $T_{\text {pump }}$ is the reversible pump turbine of the pumped storage power station life cycle.

\subsection{Restrictions}

(1) Constraints on the number of wind turbines are as follows:

$$
0 \leq N_{w} \leq N_{w \max }
$$

In the formula, $N_{w}$ is the number of wind turbines and $N_{w \max }$ is the upper limit of the number of wind turbines.

(2) Constraints on the number of photovoltaic cells are as follows: 


$$
0 \leq N_{p} \leq N_{p \max }
$$

In the formula, $N_{p}$ is the number of photovoltaic cells in a photovoltaic power station and $N_{p \max }$ is the upper limit of the number of photovoltaic cells in a photovoltaic power station.

(3) Constraints on upper reservoir capacity of pumped storage power station are as follows:

$$
0 \leq V_{\text {pump_cap }} \leq V_{\text {pump_capmax }} \text {. }
$$

In the formula, $V_{\text {pump_cap }}$ is the volume of the upper reservoir of the pumped storage power station and $V$ pump_capmax $i s$ the upper limit of the volume of the upper reservoir of the pumped storage power station.

(4) Constraints on installed capacity of pumped storage power plants are as follows:

$$
0 \leq P_{\text {pump_power }} \leq P_{\text {pump_powermax }}
$$

In the formula, $P_{\text {pump_power }}$ is the total installed capacity of the turbines of the pumped storage power station and $P_{\text {pump_powermax }}$ is the upper limit of the total installed capacity of the turbines of the pumped storage power station. The downstream capacity is assumed to be sea level with unlimited storage capacity. The maximum capacity constraint of the pumping mode of the pumped storage power station is much smaller than that of the lower reservoir, so it is feasible to assume that the lower reservoir is at sea level.

8.3. Low-Level Optimization Model. The lower-level optimization goal is the maximum annual revenue of the system, which can be expressed as

$$
\max \left(C_{\mathrm{e}}\right)=\max \left\{\sum_{n=1}^{365} \sum_{i=1}^{24} C_{c o_{2}}(t)+C(t) \cdot\left[P_{w p}(t)+P_{p v}(t)-P_{\text {pump }}(t)\right]\right\}
$$

In the formula, $C(t)$ is the electricity price at time $t$; $C_{\mathrm{Co}_{2}}(t)$ is the carbon trading revenue at time $t ; P_{w p}(t)$ is the on-grid power of wind power generation at time $t ; P_{p v}(t)$ is the on-grid power of photovoltaic power generation at time $t$; and $P_{\text {pump }}(t)$ is the power sold by the pumped storage power station.

\subsection{Restrictions.}

(1) Operational power constraints of pumped storage power stations are as follows:

$$
\left\{\begin{array}{l}
0 \leq P_{\text {pump }}(t) \leq \min \left(\frac{P_{\text {pumpmax }}, E_{\text {pumpmax }}}{h}\right), \\
\max \left(\frac{-P_{\text {pumpmax }},-E_{\text {pumpmax }}}{h}\right) \leq P_{\text {pump }}(t) \leq 0 .
\end{array}\right.
$$

In the formula, $P_{\text {pumpmax }}$ is the maximum installed capacity of the reversible pump turbine of the pumped storage power station and $E_{\text {pumpmax }}$ is the power generation corresponding to the maximum volume of the upper reservoir of the pumped storage power station.

(2) Constraints on upper reservoir capacity are as follows:

$$
0 \leq \sum_{t=1}^{N_{t}} P_{\text {pump }}(t)+\frac{E_{\text {pumpmax }}}{2} \leq E_{\text {pumpmax }}
$$

It ensures that, at any time, the storage capacity of the upstream reservoir of the pumped storage power station shall not exceed the volume of the upper reservoir. In addition, the water volume of the upper reservoir at the initial moment shall not exceed half of the set storage volume.

(3) Constraints on water inflow and outflow are as follows:

$$
\sum_{t=1}^{N_{t}} P_{\text {pump }}(t)=0
$$

The inflow and outflow of the pumped storage power station during the constraint period are the same.

\section{Two-Level Optimization Model-Solving Method Based on Linearly Decreasing Inertia Weight and Sequential Quadratic Programming Method}

The low-carbon economic double-layer optimization model of the new energy-pumped storage system is a nonlinear problem. Linearly decreasing inertia weight (LDIW) and sequential quadratic programming (SQP) are used in this paper to solve the upper and lower models. The upper-level optimization model first determines the equipment parameters and upper and lower limits of the capacity of the new energy-pumped storage combined system, and it randomly generates particle swarms that meet the capacity constraints. Then, it defines the initial value of the particle's flying speed according to the capacity constraint, so that it has the space and position state to search for the optimal solution. In the iterative process, the particle will optimize its position based on the two extreme values. One is the optimal solution $p_{i, j}$ of individual particles, and the other is the group optimal solution $p_{g, j}$ of the particle swarm after 
comparing the results of each iteration. Then, the particle adjusts its own speed and position according to the following equations $[21,23]$.

$$
\begin{aligned}
v_{i, j}(t+1)= & w v_{i, j}(t)+c_{1} r_{1}\left[p_{i, j}-x_{i, j}(t)\right] \\
& +c_{2} r_{2}\left[p_{g, j}-x_{i, j}(t)\right] \\
x_{i, j}(t+1)= & x_{i, j}(t)+v_{i, j}(t+1), \\
j= & 1,2, \ldots, n,
\end{aligned}
$$

where $i$ is the number of particles; $j$ is the dimension of the problem; $v_{i, j}(t)$ is the velocity of the $i$-th particle in the $j$-th dimension; $w$ is the inertia weight; $c_{1}$ and $c_{2}$ are the cognitive learning factor and the social learning factor, respectively; and $r_{1}$ and $r_{2}$ are random numbers between 0 and 1.

Under a given capacity configuration, the SQP algorithm is used to solve the optimal operation problem under the conditions of the pumped storage power station meeting operating power constraints, upper reservoir capacity constraints, and water inflow and outflow constraints, so as to achieve the optimization goal of maximizing system revenue [22].

For pumped storage power plants to meet the operating power constraints, upper reservoir capacity constraints, and water inflow and outflow constraints, the approximate solution under certain conditions is used as the optimization objective, and a group of QP subproblems under the constraints of close proximity in the linear case is constructed at the initial iteration point. Determine the search step size according to its iterative direction, and iterate repeatedly through the subproblems to find the operating mode of the system with the maximum profit. The process of solving the two-layer optimization model based on LDIW and SQP is shown in Figure 3.

\section{Case Analysis}

The historical data of a pumped storage power station in northern China is used in this article. Combined with the wind and photovoltaic power generation data in the region, a new energy-pumped storage joint system low-carbon economic operation simulation model is established. According to load demand and weather data, $850 \mathrm{~kW}$ wind turbines and $0.2 \mathrm{~kW} /$ piece photovoltaic cells were selected. Typical daily wind power and photovoltaic output curves are shown in Figure 4, and peak-valley time-of-use electricity price curves are shown in Figure 5.

The equipment cost and life cycle of the new energypumped storage combined system are shown in Table 1. In addition, the investment costs of photovoltaic cells, pumped storage power stations, and upper reservoir follow the scale effect. When the equipment production reaches a certain level, due to the organic combination of production factors, the equipment production cost decreases. The scale effect curve is shown in Figure 6.

In order to verify the effectiveness of the proposed model, the following two scenarios are set up in this article for comparative analysis.
Scenario 1: there is no pumped storage power station, with independent operation of wind power and photovoltaic power.

Scenario 2: there is a pumped storage power station, and a new energy-pumped storage joint system is adopted for low-carbon economic operation.

Via the equipment cost and life cycle of the new energypumped storage combined system in Table 1 and the investment cost scale effect curve in Figure 7, scenarios 1 and 2 are solved, respectively, and the optimized configuration scheme is shown in Table 2.

It can be seen that the capacity configuration of photovoltaic and wind power generation has been significantly changed by the new energy-pumped storage combined lowcarbon economic operation mode, which in turn affects the economics of the system.

Figure 7 shows the load curves in the two scenarios. Scenario 1 is a typical daily load curve, and the peak-tovalley difference is large. The load curve of scenario 2 tends to be smooth. It can be seen that the new energy-pumped storage combined low-carbon economic operation strategy effectively suppresses load fluctuations and achieves peak shaving and valley filling.

According to Figure 4, the output of wind power and photovoltaic power generation of the new energy-pumped storage combined system is given. Starting at 06:00, photovoltaics began to produce electric energy. At this time, the output of the wind turbines gradually decreased. At 12:30, the output of photovoltaics reached the peak value and continued until 19:00 when the photovoltaics stopped generating electricity. At this time, the output of the wind turbines began to increase. Renewable energy consumption capacity is shown in Figure 8. It can be seen that after adopting the low-carbon economic operation mode of the new energy-pumped storage combined system, the margin of wind power generation output has been shifted, and more than 95\% of wind power and photovoltaic power generation have been consumed.

In order to measure the superiority of the two-layer optimization model solution method based on linearly decreasing inertia weight and sequential quadratic programming method proposed in this paper, under the same scale, traditional particle swarm optimization (PSO) and genetic algorithm (GA) are used to solve the two-layer optimization model. The optimization model is solved many times to obtain the optimal solution. The algorithm parameter settings are shown in Table 3.

For the total input cost recovery period RY and its calculation time $t$, the comparison of the three algorithms is shown in Table 4.

It can be seen that the GA algorithm has the longest total investment cost recovery period and the worst optimization effect. The optimization result of PSO algorithm is close to that of LDIW, but the calculation time is the longest. Therefore, the optimization result of the LDIW algorithm is significantly better than those of the other two algorithms, and the calculation time is the fastest. The LDIW algorithm is used to solve the effectiveness of the upper model of the low-carbon economic double-layer optimization model of the new energy-pumped storage system. 


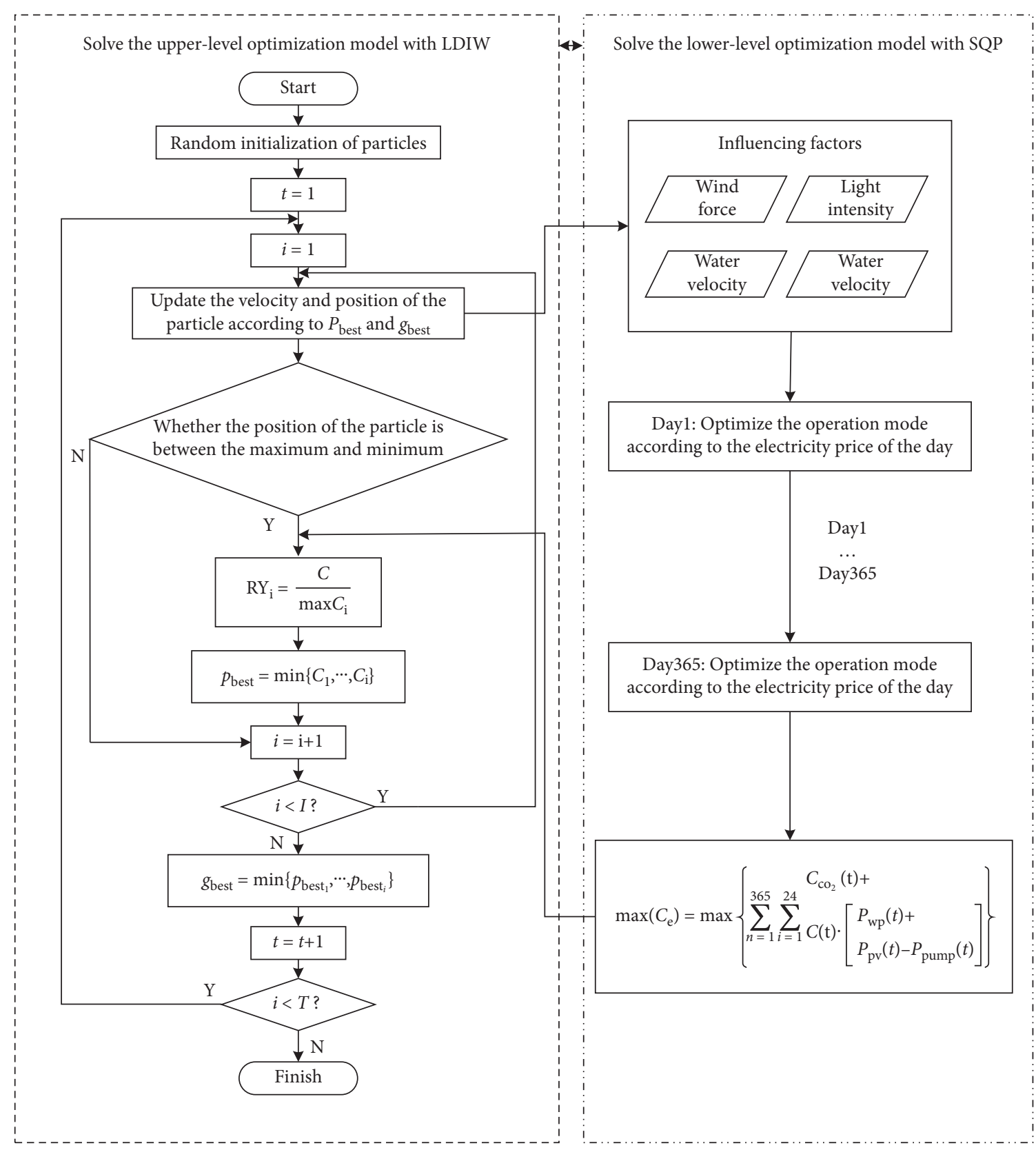

FIGURE 3: Solving method of two-layer optimization model based on LDIW and SQP. 


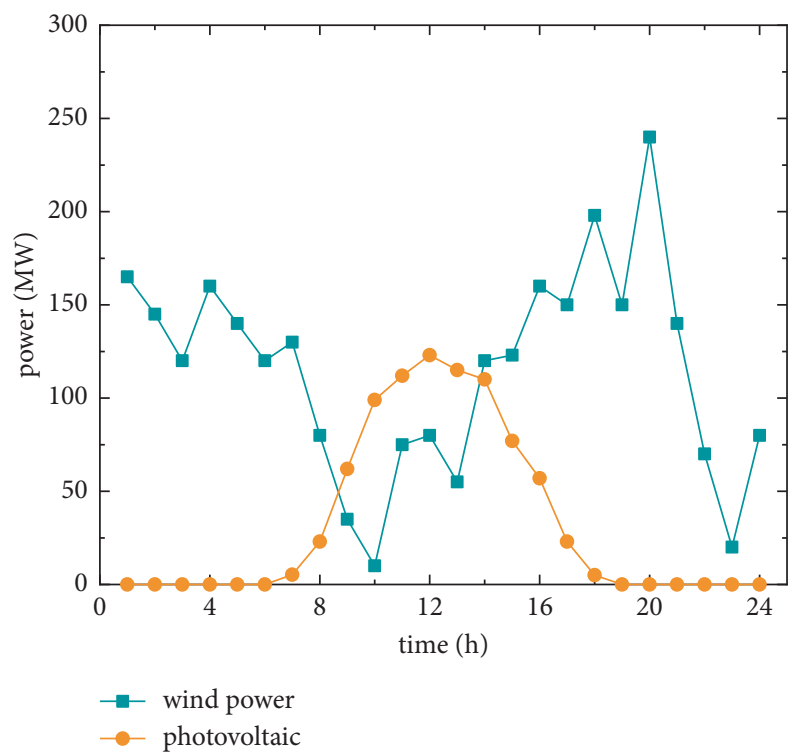

FIgURE 4: Typical daily wind power and photovoltaic output curve.

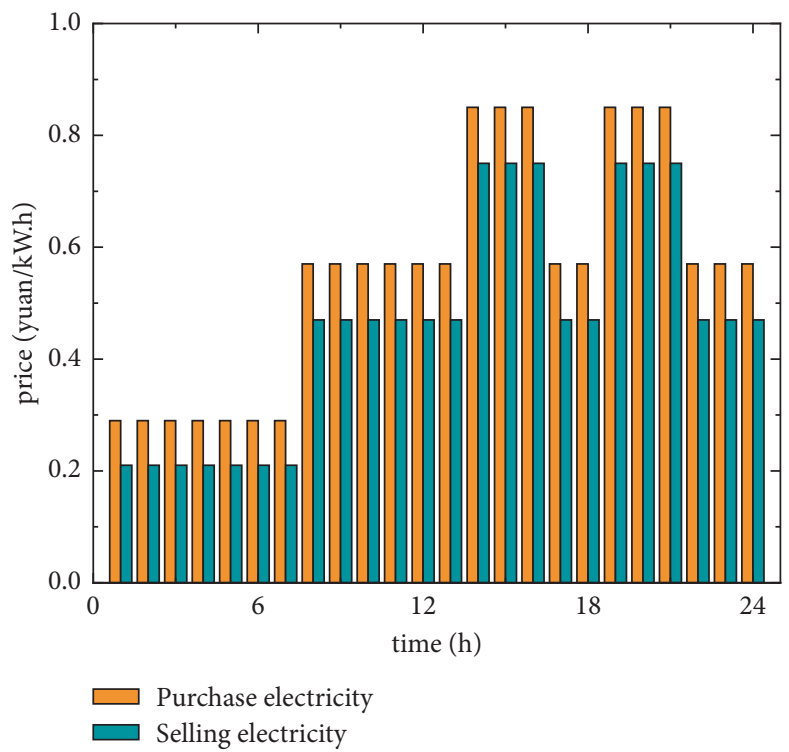

FIGURE 5: Peak-to-valley time-of-use electricity price curve.

TABLE 1: Temperature and wildlife count in the three areas covered by the study.

\begin{tabular}{|c|c|c|c|c|}
\hline Equipment & $\begin{array}{l}\text { Investment cost } \\
\text { (yuan) }\end{array}$ & $\begin{array}{l}\text { Operation and maintenance cost } \\
\text { (yuan/year) }\end{array}$ & $\begin{array}{c}\text { Replacement cost } \\
\text { (yuan) }\end{array}$ & $\begin{array}{c}\text { Life cycle } \\
\text { (years) }\end{array}$ \\
\hline Wind turbine/unit & 6321235 & 632120 & 6321235 & 10 \\
\hline Photovoltaics/unit & 1150 & 11.5 & 1150 & 15 \\
\hline Upper reservoir $/ \mathrm{m}^{3}$ & 1370 & 13.7 & 1 & 25 \\
\hline $\begin{array}{l}\text { Reversible water pump-turbine } \\
\text { generator set } / \mathrm{kW}\end{array}$ & 2000 & 20 & 2000 & 15 \\
\hline
\end{tabular}




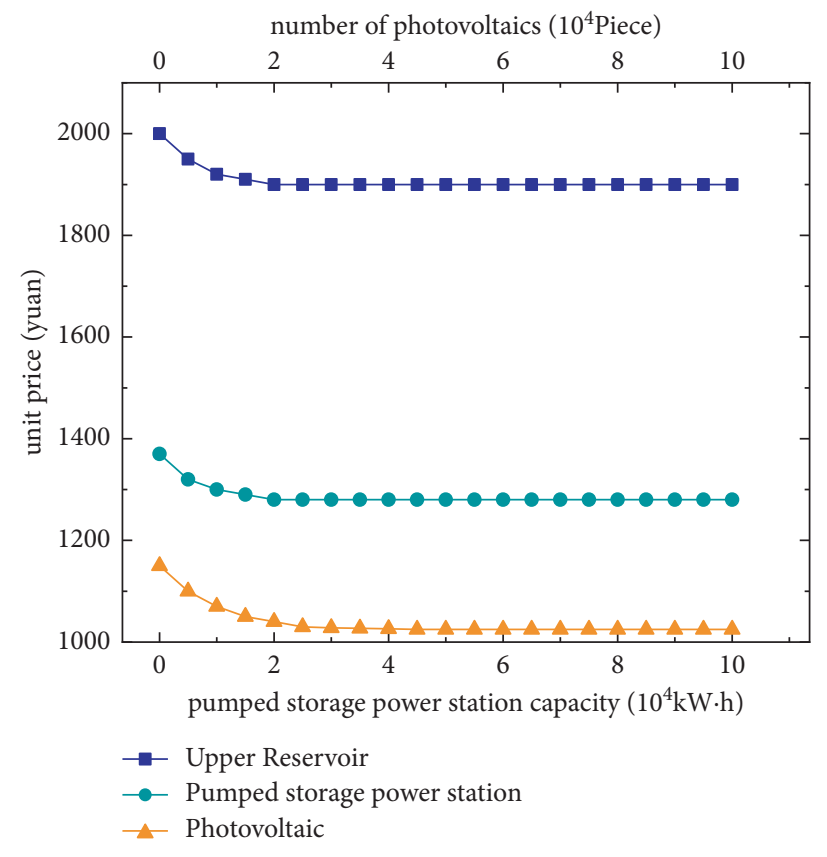

FIgURE 6: Investment cost scale effect curve.

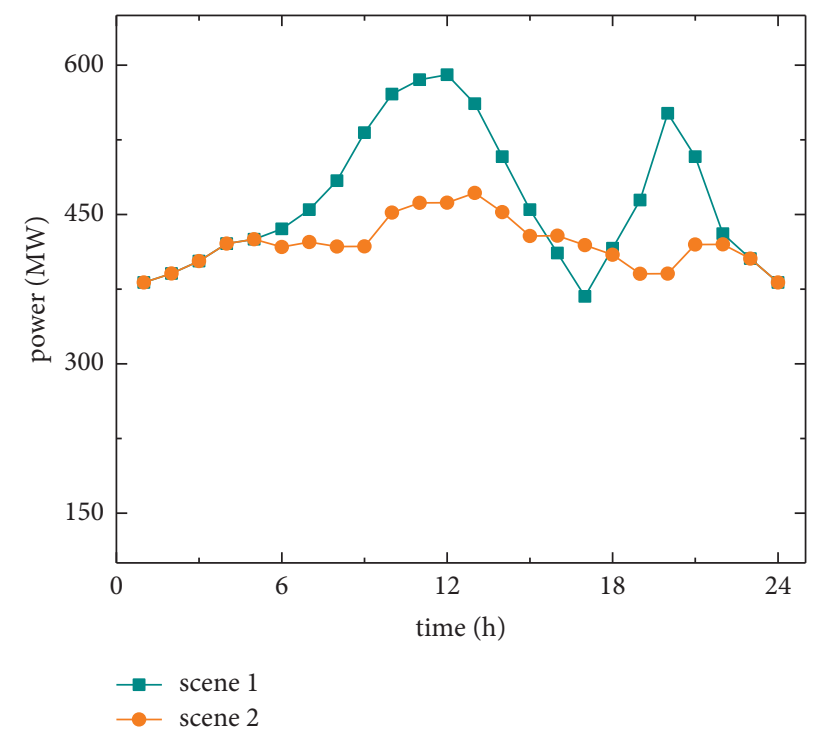

Figure 7: Load curve in two scenarios.

TABle 2: Capacity configuration schemes in two scenarios.

\begin{tabular}{|c|c|c|}
\hline Configuration & Scene 1 & Scene 2 \\
\hline The capacity of the upper reservoir of the pumped storage power station can be generated $(\mathrm{kW} \cdot \mathrm{h})$ & 1 & 5200 \\
\hline Installed capacity of pumped storage power station $(\mathrm{kW})$ & l & 1500 \\
\hline Number of photovoltaic power station cells/piece & 453211 & 295467 \\
\hline Wind turbine/set & 207 & 67 \\
\hline Upper objective function (years) & 14.61 & 10.31 \\
\hline Lower objective function (ten thousand yuan) & 166.06 & 420.96 \\
\hline
\end{tabular}




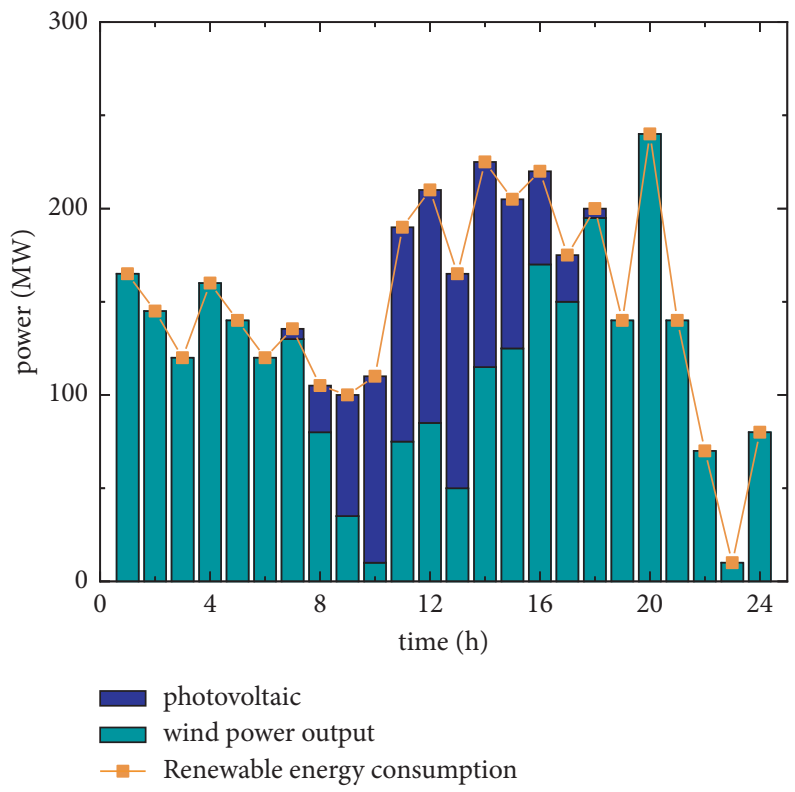

Figure 8: Renewable energy consumption capacity.

TABle 3: Algorithm parameter setting.

\begin{tabular}{|c|c|c|c|c|c|c|}
\hline Algorithm & & & Parame & & & \\
\hline \multirow[t]{2}{*}{ LDIW } & $\begin{array}{l}\text { Population } \\
\text { size }\end{array}$ & $\begin{array}{l}\text { Number of } \\
\text { iterations }\end{array}$ & Learning factor & $\begin{array}{c}\text { Maximum inertia } \\
\text { weight }\end{array}$ & $\begin{array}{c}\text { Minimum inertia } \\
\text { weight }\end{array}$ & l \\
\hline & 10 & 30 & 2 & 0.9 & 0.4 & l \\
\hline \multirow[t]{2}{*}{ PSO } & $\begin{array}{l}\text { Population } \\
\text { size }\end{array}$ & $\begin{array}{l}\text { Number of } \\
\text { iterations }\end{array}$ & Learning factor & Inertia weight & l & l \\
\hline & 10 & 30 & 2 & 0.5 & l & I \\
\hline \multirow[t]{2}{*}{ GA } & $\begin{array}{l}\text { Population } \\
\text { size }\end{array}$ & $\begin{array}{l}\text { Number of } \\
\text { iterations }\end{array}$ & $\begin{array}{l}\text { Individual } \\
\text { length }\end{array}$ & Generation gap & Crossover probability & $\begin{array}{l}\text { Mutation } \\
\text { probability }\end{array}$ \\
\hline & 10 & 30 & 20 & 0.9 & 0.7 & 0.01 \\
\hline
\end{tabular}

TABLE.4: Comparison of algorithm results.

\begin{tabular}{lcr}
\hline Algorithm & RY/year & t/s \\
\hline LDIW & 10.31 & 107688 \\
PSO & 10.89 & 129855 \\
GA & 11.53 & 120632 \\
\hline
\end{tabular}

\section{Conclusions}

In the context of a high proportion of renewable energy connected to the power system, a new energy-pumped storage combined system model consisting of wind power, photovoltaic power, and pumped storage power stations has been established. Combined with the carbon quota trading mechanism, a new energy-pumped storage combined system low-carbon economy double-layer optimization model is proposed. Finally, based on the historical data of a pumped storage power station in northern China, the proposed method was simulated and verified, and the following conclusions were obtained:

(1) The carbon trading mechanism is introduced, with investment costs and system revenue as the upper and lower optimization targets, the optimization of capacity allocation and operation are combined, and the economy of the system is effectively improved.

(2) A new energy-pumped storage joint operation method is proposed to make the originally fluctuating wind and photovoltaic power generation a stable and dispatchable multisource energy storage system, load fluctuations are smoothed, and peak shifting and valley shifting are realized.

(3) The phenomenon of abandoning wind and light in the system is alleviated, and the ability to absorb renewable energy is effectively improved.

\section{Data Availability}

The datasets generated for this study are available on request to the corresponding author. 


\section{Conflicts of Interest}

The authors declare that the research was conducted in the absence of any commercial or financial relationships that could be construed as potential conflicts of interest.

\section{Acknowledgments}

This work was supported by State Grid Xinyuan Holdings Pushihe Company research and application services of key technologies for power station peak regulation assistance and multidimensional monitoring based on big data analysis (SGXYPH00YJJS2100149).

\section{References}

[1] X. Zhou, S. Chen, Z. Lu, and Y. Hang, "Technology features of the new generation power system in China," Proceedings of the CSEE, vol. 38, no. 7, pp. 1893-1904, 2018.

[2] T. Ding, C. Mu, and Z. Bie, "Review of energy internet and its operation," Proceedings of the CSEE, vol. 38, no. 15, pp. 4318-4328, 2018.

[3] L. Zhang, A. Chen, G. U. Gu, X. Wang, D. Xie, and C. Gu, "Planning of the multi-energy circular system coupled with waste processing base: a case from China," Energies, vol. 12, no. 20 , p. 3910, 2019.

[4] S. Rehman, L. M. Al-Hadhrami, and M. M. Alam, "Pumped hydro energy storage system: a technological review," Renewable and Sustainable Energy Reviews, vol. 44, pp. 586-598, 2015.

[5] Z. Jing, R. Hu, Z. Yuan, and Q. H. Wu, "Capacity configuration optimization for island microgrid with wind/solar/ pumped storage considering demand response," Automation of Electric Power Systems, vol. 41, no. 1, pp. 65-72, 2017.

[6] X. Xu, W. Hu, D. Cao, Q. Huang, C. Chen, and Z. Chen, "Optimized sizing of a standalone PV-wind-hydropower station with pumped-storage installation hybrid energy system," Renewable Energy, vol. 147, pp. 1418-1431, 2020.

[7] R. Wang, Q. Sun, D. Ma, and X. Hu, "Line impedance cooperative stability region identification method for grid-tied inverters under weak grids," IEEE Transactions on Smart Grid, vol. 11, no. 4, pp. 2856-2866, 2020.

[8] H. Chen, Z. Xue, Z. Ma et al., "Performance analysis on wind and solar power generation system combined with energy storage system," Thermal Power Generation, vol. 48, no. 7, pp. 103-109, 2019.

[9] T. Ma, H. Yang, L. Lu, and J. Peng, "Optimal design of an autonomous solar-wind-pumped storage power supply system," Applied Energy, vol. 160, pp. 728-736, 2015.

[10] Z. Hu, H. Ding, and T. Kong, "A joint daily operational optimization model for wind power and pumped-storage plant," Automation of Electric Power Systems, vol. 36, no. 2, pp. 36-41, 2012.

[11] S. Luo, W. Hu, H. Qi, H. Xiaoyan, and C. Zhe, "Optimization of photovoltaic/small hydropower/pumped storage power station system sizing under the market mechanism," Transactions of China Electrotechnical Society, vol. 35, no. 13, pp. 2792-2804, 2020.

[12] J. Gao, Y. Zheng, J. Li, X. Zhu, and K. Kan, “Optimal model for complementary operation of a photovoltaic-wind-pumped storage system," Mathematical Problems in Engineering, vol. 2018, pp. 1-9, 2018.
[13] Q. Zhu, L. Zeng, and F. Kou, "Research on optimal allocation method of wind, photovoltaic, gas turbine and energy storage in industrial parks considering energy storage's grid-connected operation modes," Power System Protection and Control, vol. 47, no. 17, pp. 23-31, 2019.

[14] M. Azaza and F. Wallin, "Multi objective particle swarm optimization of hybrid micro-grid system: a case study in Sweden," Energy, vol. 123, pp. 108-118, 2017.

[15] P. Wais, "Two and three-parameter Weibull distribution in available wind power analysis," Renewable Energy, vol. 103, pp. 15-29, 2017.

[16] R. Wang, Q. Sun, D. Ma, Y. Gui, D. Qin, and P. Wang, "Reduced-order transfer function model of the droop-controlled inverter via Jordan continued-fraction expansion," IEEE Transactions on Energy Conversion, vol. 35, no. 3, pp. 1585-1595, 2020.

[17] L. Guan, Q. Zhao, B. Zhou, and Y. Lyu, "Multi-scale clustering analysis based modeling of photovoltaic power characteristics and its application in prediction," Automation of Electric Power Systems, vol. 42, no. 15, pp. 24-30, 2018.

[18] X. Dong, G. Yang, and Y. Wang, "Low carbon economic dispatch of power system with wind and solar generation based on carbon trading," Electrical Drive Automation, vol. 40, no. 1, pp. 13-16, 2018.

[19] R. Wang, Q. Sun, D. Ma, and Z. Liu, “The small-signal stability analysis of the droop-controlled converter in electromagnetic timescale," IEEE Transactions on Sustainable Energy, vol. 10, no. 3, pp. 1459-1469, 2019.

[20] J. Zhu, L. Chen, X. Wang, and L. Yu, "Bi-level optimal sizing and energy management of hybrid electric propulsion systems," Applied Energy, vol. 260, pp. 114-134, 2020.

[21] X. Lin, Y. Zhang, and B. Chen, "Bi-level optimal configuration of park energy internet considering multiple evaluation indicators," Automation of Electric Power Systems, vol. 43, no. 20, pp. 8-15, 2019.

[22] Y. Xu, Q. Liao, D. Liu, Y. Tian, W. Chen, and Y. Chen, "Bilevel integrated energy planning method considering active management measures in electricity market environment," Automation of Electric Power Systems, vol. 42, no. 18, pp. 114-126, 2018.

[23] Q. Zeng, B. Zhang, J. Fang, and Z. Chen, "A bi-level programming for multistage co-expansion planning of the integrated gas and electricity system," Applied Energy, vol. 200, pp. 192-203, 2017. 